\title{
The epidemiology of non-viral gastroenteritis in New Zealand children from 1997 to 2015: an observational study
}

\author{
Emma Jeffs ${ }^{1 \dagger}$, Jonathan Williman ${ }^{2 \dagger}$, Natalie Martin ${ }^{1}$, Cheryl Brunton ${ }^{2}$ and Tony Walls ${ }^{1 * \dagger}$
}

\begin{abstract}
Background: Acute gastroenteritis is a substantial cause of hospitalization in children. Shigella, Salmonella, Campylobacter, Yersinia, enterotoxigenic Escherichia coli (ETEC), Giardia and Cryptosporidium are gastrointestinal pathogens that are notifiable in New Zealand (NZ). The impact of these infections in the pediatric population has not yet been analyzed. The aim of this study was to describe the epidemiological trends in disease notifications and hospital admissions due to nonviral gastroenteritis in NZ children.
\end{abstract}

Methods: In this population-based descriptive study, age-specific and age-standardized notification and hospital admission rates were analyzed from 1997-to-2015 for Shigella, Salmonella, Campylobacter, Yersinia, ETEC, Giardia and Cryptosporidium infections in children $<15$ years of age. Variations in disease by gender, age, ethnicity and geography were described.

Results: From 1997-to-2015 there were 74,454 notifications (57.6\% male) and 3192 hospitalizations (56.4\% male) due to non-viral gastroenteritis in NZ children aged $<15$ years. There was an overall trend towards a reduction in disease notifications and hospitalizations, however each disease showed a unique pattern of change over time. Campylobacter was the pathogen most frequently notified, accounting for $51.7 \%$ of notifications and $43.4 \%$ of hospitalizations. The hospitalization-to-notification ratios were, from highest to lowest, Salmonella typhi (1:1.09), Shigella (1:4.0), ETEC (1:7.81), nontyphoidal Salmonella (1:13.1), Campylobacter (1:27.8), Yersinia (1:29.2), Cryptosporidium $(1,33.4)$, and Giardia $(1,72.5)$. Compared to females, male notification rates were approximately $40 \%$ higher for Campylobacter, 25\% higher for Giardia and Yersinia, and 15\% higher for Cryptosporidium and nontyphoidal Salmonella $(p<0.001)$. Notification rates were highest in children 1-4 years, with the exceptions of nontyphoidal Salmonella, Salmonella typhi and Yersinia. Notification rates for nontyphoidal Salmonella and Yersinia were highest in children < 1 year, and for Salmonella typhi those aged 5-9 years. Children $<1$ year were most likely to be hospitalized.

Conclusions: The incidence of non-viral gastroenteritis in NZ children reduced during the 19-year period considered. The burden of disease was highest in the community, with only a small percentage of cases requiring hospitalization. This study provides important insight into the non-viral causes of gastroenteritis in NZ children and how environmental influences and changes in food safety practices may have helped to reduce the burden of these diseases in children.

Keywords: Epidemiology, Bacterial gastroenteritis, Protozoal gastroenteritis, Campylobacter, Shigella, Salmonella, Yersinia, Escherichia coli, Giardia, Cryptosporidium

\footnotetext{
* Correspondence: tony.walls@otago.ac.nz

tEmma Jeffs, Jonathan Williman and Tony Walls contributed equally to this work.

${ }^{1}$ Department of Paediatrics, University of Otago, PO Box 4345, Christchurch

Mail Centre, Christchurch 8140, New Zealand

Full list of author information is available at the end of the article
}

(c) The Author(s). 2019 Open Access This article is distributed under the terms of the Creative Commons Attribution 4.0 International License (http://creativecommons.org/licenses/by/4.0/), which permits unrestricted use, distribution, and reproduction in any medium, provided you give appropriate credit to the original author(s) and the source, provide a link to the Creative Commons license, and indicate if changes were made. The Creative Commons Public Domain Dedication waiver (http://creativecommons.org/publicdomain/zero/1.0/) applies to the data made available in this article, unless otherwise stated. 


\section{Background}

Acute gastroenteritis is a common illness and a substantial cause of hospitalization in previously healthy young children. In their first three years of life, almost all children will experience at least one episode of acute gastroenteritis [1]. Most cases are self-resolving and do not require treatment, however, older people and young children are at an increased risk of complications. Morbidity due to gastroenteritis is greatest in children aged younger than five years [2].

A diverse range of pathogens are implicated in childhood gastroenteritis including viruses, bacteria and protozoa. Viral infections, and rotavirus in particular, account for the greatest burden of gastrointestinal disease in young children worldwide [3]. In December 2009, the World Health Organization (WHO) recommended that all infants should be routinely immunized to prevent rotavirus disease [4]. The rotavirus vaccination was introduced into the New Zealand (NZ) national schedule in 2014. This has led to a significant reduction in the incidence of viral gastroenteritis in NZ children [5]. Studies reporting the epidemiology of pediatric gastroenteritis in NZ have focused largely on rotavirus and other viral pathogens $[5,6]$. There are no published studies reporting on the epidemiology of non-viral gastroenteritis in NZ children.

The total burden of disease due to foodborne and waterborne gastrointestinal infection in NZ is high. There are an estimated 4.17 to 5.16 million cases of acute gastroenteritis annually, and the incidence of disease in the community is estimated at 1.11 episodes per person per year $[7,8]$. NZ has a notifiable disease monitoring system whereby certain communicable diseases for which investigation and public health action are required are notifiable to the local Medical Officer of Health. Diseases may be made notifiable by the Ministry of Health $(\mathrm{MoH})$. This may be to allow prompt public health action, such as the provision of prophylaxis to contacts (eg. Meningococcal disease), to allow for environmental investigation of potential sources (eg. food and water borne diseases) or to monitor the incidence of vaccine preventable diseases (eg, mumps, measles, rubella). Some diseases are also notifiable as part of NZ's commitment to implementation of the International Health Regulations (eg. Yellow Fever, Middle Eastern Respiratory Syndrome (MERS)).

Data on notifiable diseases are reported to The Institute of Environmental Science and Research (ESR) for disease surveillance and monitoring on behalf of the NZ MOH. ESR is one of ten NZ Crown Research Institutes (CRI) established in 1992, after the reorganisation of the Government-owned Department of Scientific and Industrial Research (DSIR) and science units from the Department of Health. As well as carrying out research, it is also responsible for surveillance and reporting of notifiable diseases in NZ. The list of notifiable disease in NZ can be found at https://www.health.govt.nz/our-work/diseases-and-conditions/notifiable-diseases [9]. Notifiable bacterial pathogens include Campylobacter, Shigella, Salmonella, Yersinia and verotoxin-producing or shiga toxin-producing enterotoxigenic Escherichia coli (ETEC), and notifiable protozoal pathogens include Giardia and Cryptosporidium. Campylobacter has been notifiable since 1980, ETEC since 1993, and all other pathogens since at least 1996 (Table 1).

Surveillance data for NZ adults suggest the incidence of notifications for bacterial gastroenteritis is decreasing over time; a trend that has been particularly evident since the mid-2000s [10]. The incidence of protozoan illness has remained static over time [10]. Campylobacter is the most frequently identified gastrointestinal pathogen, followed by nontyphoidal Salmonella and Giardia [11]. Campylobacter is the most frequently notified gastroenteric disease in NZ and accounts for at least 35\% of all notifiable disease reports (158.9 cases per 100,000 in the population in 2016) [10]. Campylobacter is also frequently implicated in outbreaks of disease, some of which have been large. For example, a recent outbreak of Campylobacter illness caused by contamination of drinking water occurred in Havelock North, NZ in August 2016, during which 5500 of the town's 14,000 residents were estimated to have become ill with the disease [12].

The NZ health system is predominantly publicly-funded with services provided by public, private and nongovernmental sectors. The country is divided into twenty District Health Boards (DHB's) that are responsible for the planning and funding of health services for their geographical areas. Primary healthcare (including general practitioners) is free for all children aged 13 years and under and is subsidized for residents and citizens. Tertiary-level care

Table 1 Year of commencement of ESR notification for diseases in this study, and ICD9-CM codes used to identify hospital admission rates

\begin{tabular}{lll}
\hline & $\begin{array}{l}\text { Year of } \\
\text { commencement } \\
\text { of ESR notification }\end{array}$ & $\begin{array}{l}\text { ICD-9-CMA-II } \\
\text { codes }\end{array}$ \\
\hline Campylobacteriosis $^{\text {Shigellosis }}{ }^{a}$ & 1980 & A04.5 \\
$\begin{array}{l}\text { Salmonellosis (including Salmonella } \\
\text { typhi and nontyphoidal Salmonella) }^{a}\end{array}$ & - & A03 \\
Yersiniosis $_{\text {Giardiasis }}$ & 1996 & A02 \\
Cryptosporidiosis $_{\text {ETEC }}{ }^{b}$ & 1996 & A04.6 \\
\hline
\end{tabular}

a - It is unclear when reporting for Shigellosis and Salmonellosis commenced, but ESR has informed the authors of this study that these have likely been notifiable since the Health Act of 1956 . Yearly totals are available to 1960 b - ETEC was notifiable from 1993 as 'food poisoning'. In 1996, this changed to being notifiable as 'acute gastroenteritis', and then in 2012 became notifiable as 'verotoxin-producing or shiga toxin-producing Escherichia coli' 
(hospitals) is free-of-charge for all and there is no requirement for private healthcare insurance. The health status of the NZ population overall is high, however, there are significant inequalities in the health of Mãori, the indigenous people [13].

Acute gastroenteritis affects children in greater numbers than adults [14], however, systematic analysis of the impact of non-viral gastroenteritis in NZ children has not been reported previously. The aim of this study was to determine the burden of disease due to non-viral gastroenteritis in NZ children by describing trends in hospital admissions and disease notifications from 1997 to 2015.

\section{Methods}

\section{Datasets}

In this population-based descriptive study that aimed to describe the epidemiological trends in disease notifications and hospital admissions due to non-viral gastroenteritis in NZ children, extracts from two data sets were analyzed for the period 1 January 1997 to 31 December 2015: The National Minimum Dataset (NMDS) and ESR's notifiable diseases database, EpiSurv. The NMDS is a national dataset of routinely collected public and private hospital discharge information that includes coded clinical data for inpatients and day patients [15]. The ESR database contains data on notifiable diseases. All cases of notifiable disease resulting in hospital admission included in the NMDS should, theoretically, also be included in ESR's database.

The NMDS was introduced in 1999. The original NMDS was implemented in 1993 and retrospectivelyloaded with public hospital discharge information from 1988 [15]. The NMDS dataset included diseases defined according to their International Classification of Diseases Clinical Modification 9 (ICD-9-CM) codes (Table 1). ESR commenced standardized online reporting in 1997 and therefore 1997 was elected as the start point for data analysis.

The data extracted from the NMDS database included: primary diagnosis (by ICD-9-CM code), provider agency code, agency name (the name of the admitting hospital), facility code, facility name, gender code, prioritized ethnic code, patient age at discharge, financial year, year of data, short stay data, month of data and number of discharges.

ESR data were obtained from a web-based portal, EpiSurv, which is NZ's national database for notifiable disease surveillance and is operated by ESR on behalf of the NZ MoH. Under the Health Act 1956, healthcare professionals are required to inform their local Medical Officer of Health on suspicion or diagnosis of a case of any notifiable disease [9]. Medical Officers of Health and local public health unit staff investigate these notifications and complete EpiSurv case report forms online. Laboratory cases are routinely submitted to ESR to be loaded onto EpiSurv.

The data extracted from the ESR database included: EpiSurv number, case status, report date, DHB, age in years, sex, ethnicity (selected and prioritized), onset date information, death details, and clinical details.

Subgroup analysis was performed for Māori children because there are significant health inequalities for this group when compared to non-Mãori, including high rates of other infections such as invasive bacterial infections (bacterial meningitis [16] and septicemia [17]), acute rheumatic fever [18], and skin and soft tissue infections [19].

Reported cases of Salmonella were subdivided in order to analyze data on nontyphoidal Salmonella and Salmonella typhi separately. Our study included non-viral causes of gastroenteritis which are notifiable under the Health Act in NZ. While cholera is a notifiable disease, it is not endemic in New Zealand, and the very occasional cases seen are in travellers from endemic countries. Helminth infestations were also not included in the study as only cestode infestations (cystercicosis, taeniasis and hydatids) are notifiable and these were uncommon in the study period.

\section{Statistical analysis}

Data were analyzed using the statistical software ' $R$ ' ( $R$ version 3.3.2 (2016-10-31)). Notifications and hospitalizations were grouped by disease, year, age (categorized as $<1$, 1 to 4,5 to 9 , and 10 to 14 years), gender (female, male), and ethnicity (Māori, non-Māori) both separately and in combinations. Where ethnicity was unknown, cases were included in total counts but excluded from ethnic comparisons. Group specific incidence rates were calculated using the estimated resident population at 30 June (derived from NZ Census data from Statistics NZ) as the denominators. Standard methods were used to directly age-standardize incidence rates to the WHO 2000-2025 population [20].

Changes in log age-standardized incidence rates of disease over time were analyzed using joinpoint regression models [21], fitted using the Joinpoint Regression Program (version 4.5.0.1) [22]. Models were allowed up to four joinpoints, with each joinpoint being no less than two years from another joinpoint or the ends of the data. These models were used to calculate the average annual percentage change (AAPC) in age-standardized incidence rates for the full data range of each disease, as well as selected time periods. The models were also used to assess differences in trends over time between selected subgroups. Comparisons in incidence rates by age, gender, and ethnicity were also investigated by using generalized additive poisson regression models to calculate incidence rate ratios with 95\% confidence intervals. Year of observation was adjusted for in models by fitting it as a penalized thin plate regression spline [23]. 


\section{Results}

\section{Overall summary}

In the 19-year period from 1997 to 2015 there were 74,454 notifications ( $57.6 \%$ male) and 3192 hospitalizations (56.4\% male) due to non-viral gastroenteritis in NZ children. Campylobacter was the disease most frequently notified and accounted for $51.7 \%$ of all notifications and $43.4 \%$ of all hospitalizations. Notification rates were highest in children aged $1-4$ years of age.

\section{Notifications versus hospitalizations}

Hospitalization rates were typically much lower than the corresponding notification rates for each disease (Fig. 1). The hospitalization to notification ratios were, in order from highest to lowest, Salmonella typhi (1:1.09), Shigella (1:4.0), ETEC (1:7.81), nontyphoidal Salmonella (1:13.1), Campylobacter (1:27.8), Yersinia (1:29.2), Cryptosporidium (1:33.4), and Giardia (1:72.5).

\section{Time trends}

Whilst there was an overall trend towards a reduction in both notifications and hospitalizations, particularly since the mid-2000s, each disease showed a unique pattern of change over time (Fig. 1, Table 2). Notification and hospitalization rates have been decreasing consistently for Shigella since at least 1997, and for nontyphoidal Salmonella since 2001 (AAPC notification since $2001=-8.20$, 95\%CI -15.08 to $-0.77, p=0.031$ ). There was weak evidence that rates were also decreasing for Cryptosporidium, whilst rates for Yersinia have remained quite stable. ETEC notifications and hospitalizations increased substantially over the study period, and Salmonella typhi hospitalization rates also increased by, on average, $4.4 \%$ per year.

There was a noticeable increase in Campylobacter notifications and hospitalizations at the beginning of the study period with age-adjusted notification rates peaking at 326 per 100,000 in 2006. Notification rates almost halved to around 171 per 100,000 in 2008 and have gradually continued to decrease to a low of 141 per 100,000 in 2015. However, Campylobacter hospitalization rates have remained around 6.6 per 100,000 since 2008. Age-adjusted notification rates for Giardia halved between 1997 and 2006 (from 88.7 to 44.2 per 100,000), but increased to 71.7 per 100,000 in 2010 before resuming on the downward

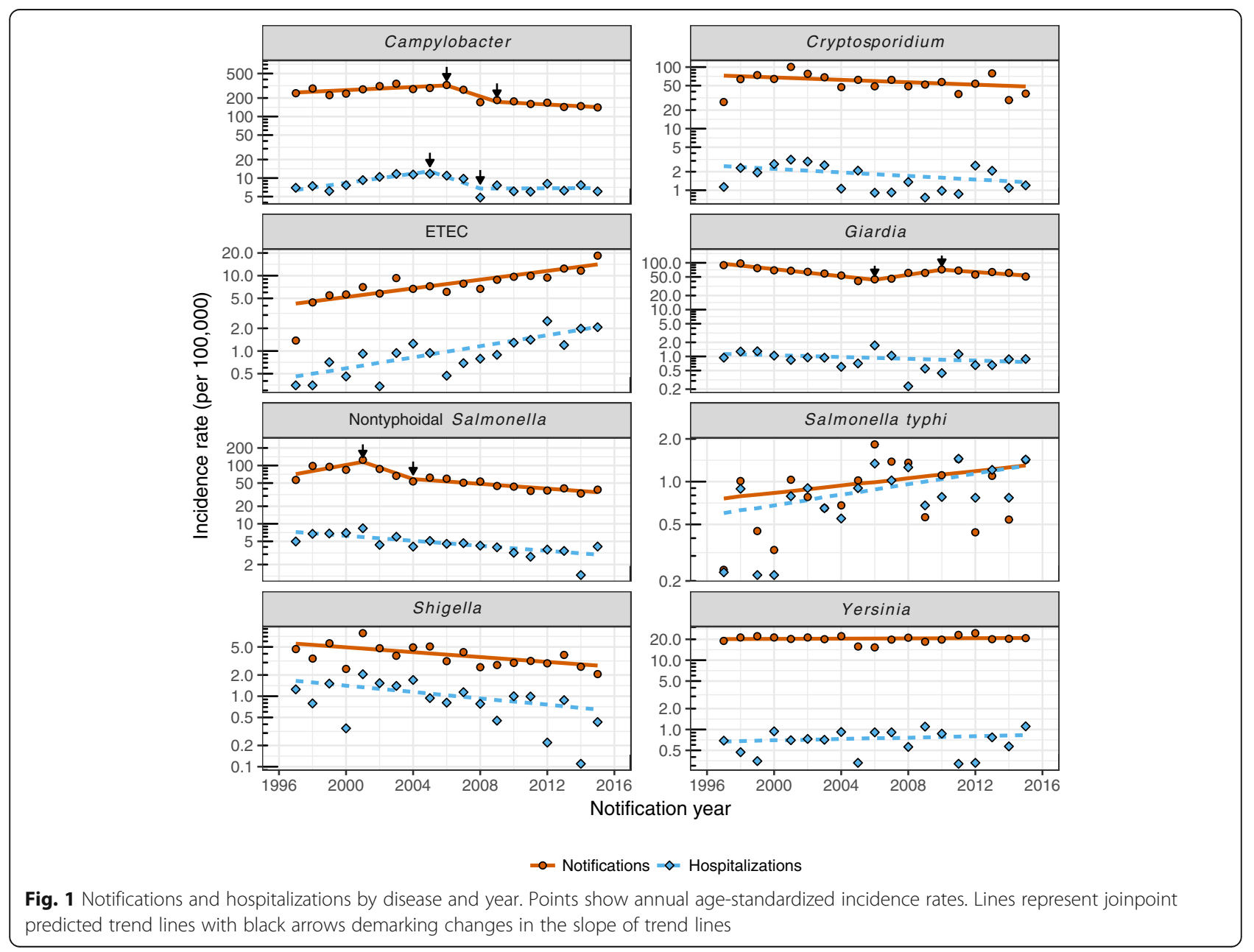


Table 2 Changes in notification and hospitalization incidence rates over time

\begin{tabular}{|c|c|c|c|c|}
\hline & Years & $\begin{array}{l}\text { Change in age } \\
\text { adjusted rate } \\
\text { (per } 100,000 \text { ) }\end{array}$ & Annual percentage change & Direction \\
\hline \multicolumn{5}{|l|}{ Notifications } \\
\hline Campylobacter & 1997 to 2006 & 239 to 326 & $3.0(0.2$ to $5.9, p=0.040)$ & $\Delta$ \\
\hline & 2006 to 2009 & 326 to 185 & $-18.6(-42.3$ to $14.9, p=0.216)$ & - \\
\hline & 2009 to 2015 & 185 to 141 & $-3.2(-9.4$ to $3.5, p=0.304)$ & - \\
\hline Cryptosporidium & 1997 to 2015 & 27.1 to 37.1 & $-2.2(-4.9$ to $0.5, p=0.103)$ & - \\
\hline ETEC & 1997 to 2015 & 1.37 to 18.4 & $6.9(4.8$ to $9.0, p=<0.001)$ & $\Delta$ \\
\hline Giardia & 1997 to 2006 & 88.7 to 44.2 & $-8.4(-10.7$ to $-6.0, p=<0.001)$ & $\nabla$ \\
\hline & 2006 to 2010 & 44.2 to 71.7 & $13.2(-2.7$ to $31.8, \mathrm{p}=0.098)$ & - \\
\hline & 2010 to 2015 & 71.7 to 50.9 & $-5.5(-11.3$ to $0.6, p=0.071)$ & - \\
\hline $\begin{array}{l}\text { Nontyphoidal } \\
\text { Salmonella }\end{array}$ & 1997 to 2001 & 56.5 to 125 & $12.8(-0.5$ to $27.9, \mathrm{p}=0.058)$ & - \\
\hline & 2001 to 2004 & 125 to 53.3 & $-20.3(-46.0$ to $17.8, p=0.227)$ & - \\
\hline & 2004 to 2015 & 53.3 to 38.7 & $-4.6(-7.7$ to $-1.4, p=0.009)$ & $\nabla$ \\
\hline Salmonella typhi & 1997 to 2015 & 0.241 to 1.42 & $3.0(-1.3$ to $7.5, p=0.163)$ & - \\
\hline Shigella & 1997 to 2015 & 4.65 to 2.06 & $-3.9(-6.4$ to $-1.3, p=0.006)$ & $\nabla$ \\
\hline Yersinia & 1997 to 2015 & 19 to 20.8 & $0.2(-0.8$ to $1.2, p=0.665)$ & - \\
\hline Hospitalisations & & & & \\
\hline Campylobacter & 1997 to 2005 & 6.95 to 11.8 & $9.2(4.9$ to $13.5, p=<0.001)$ & $\Delta$ \\
\hline & 2005 to 2008 & 11.8 to 4.82 & $-19.4(-42.0$ to $12.0, p=0.177)$ & - \\
\hline & 2008 to 2015 & 4.82 to 6.07 & $0.3(-5.0$ to $5.8, \mathrm{p}=0.918)$ & - \\
\hline Cryptosporidium & 1997 to 2015 & 1.13 to 1.2 & $-3.3(-6.8$ to $0.4, p=0.077)$ & - \\
\hline ETEC & 1997 to 2015 & 0.35 to 2.07 & $8.8(5.5$ to $12.3, p=<0.001)$ & $\Delta$ \\
\hline Giardia & 1997 to 2015 & 0.936 to 0.884 & $-2.2(-5.2$ to $0.9, \mathrm{p}=0.155)$ & - \\
\hline $\begin{array}{l}\text { Nontyphoidal } \\
\text { Salmonella }\end{array}$ & 1997 to 2015 & 4.97 to 4.07 & $-4.8(-6.8$ to $-2.8, \mathrm{p}=<0.001)$ & $\nabla$ \\
\hline Salmonella typhi & 1997 to 2015 & 0.23 to 1.43 & $4.4(0.8$ to $8.1, p=0.020)$ & $\Delta$ \\
\hline Shigella & 1997 to 2015 & 1.25 to 0.434 & $-5.1(-9.1$ to $-0.9, p=0.021)$ & $\nabla$ \\
\hline Yersinia & 1997 to 2015 & 0.695 to 1.11 & $1.2(-2.1$ to $4.5, p=0.466)$ & - \\
\hline
\end{tabular}

trend. Interestingly, Giardia hospitalization rates did not appear to follow this pattern.

\section{Comparisons by age}

Notification rates were highest in children aged $1-4$ years of age, with the exceptions of nontyphoidal Salmonella, Salmonella typhi and Yersinia. Notification rates for nontyphoidal Salmonella and Yersinia were highest in infants aged under 1 year, and for Salmonella typhi in those aged 5-9 years (Table 3). Whilst notifications for Campylobacter were more frequent in the 1-4 year age group, those under 1 year were most likely to be hospitalized. For all other diseases, differences by age in hospitalization rates were broadly similar to differences in notifications.

\section{Comparison by gender}

Compared to females, male notification rates were approximately 40\% higher for Campylobacter, 25\% higher for Giardia and Yersinia, and 15\% higher for Cryptosporidium and nontyphoidal Salmonella $(p<0.001$ in all cases, Table 4). There was no evidence for a difference in notification rates for ETEC, Salmonella typhi, or Shigella ( $p>0.8$ in all cases). Differences in hospitalization rates were only observed potentially due to the relatively low numbers of cases for the other diseases.

\section{Comparisons by Māori}

Approximately $20 \%$ of cases were missing ethnicity data in EpiSurv records prior to 2009, but the proportion of 
Table 3 Differences in notification $(\mathrm{N})$ and hospitalization $(\mathrm{H})$ rates by age group as compared to those aged 10-14 years. Values represent incidence rate ratios ( $95 \%$ confidence intervals) adjusted by year and gender

\begin{tabular}{lllll}
\hline Disease & Source & Age, $<1$ years & Age, 1 to 4 years & Age, 5 to 9years \\
\hline Campylobacter & $\mathrm{N}$ & $2.53(2.43,2.63)$ & $3.09(3.01,3.18)$ & $1.18(1.14,1.21)$ \\
Cryptosporidium & $\mathrm{H}$ & $2.25(1.89,2.68)$ & $1.52(1.33,1.73)$ & $0.76(0.65,0.88)$ \\
& $\mathrm{N}$ & $2.53(2.28,2.81)$ & $7.03(6.58,7.51)$ & $2.11(1.96,2.27)$ \\
ETEC & $\mathrm{H}$ & $2.85(1.65,4.92)$ & $5.38(3.74,7.74)$ & $2.18(1.47,3.23)$ \\
& $\mathrm{N}$ & $8.33(6.50,10.7)$ & $11.0(8.9,13.5)$ & $2.17(1.71,2.75)$ \\
Giardia & $\mathrm{H}$ & $5.56(2.94,10.5)$ & $7.20(4.37,11.9)$ & $1.85(1.04,3.28)$ \\
& $\mathrm{N}$ & $4.12(3.71,4.57)$ & $10.6(9.82,11.4)$ & $3.25(3.00,3.52)$ \\
Nontyphoidal Salmonella & $\mathrm{H}$ & $5.34(2.85,10.0)$ & $5.35(3.24,8.82)$ & $1.43(0.79,2.57)$ \\
& $\mathrm{N}$ & $6.52(6.06,7.02)$ & $5.31(4.99,5.65)$ & $1.63(1.52,1.75)$ \\
Salmonella typhi & $\mathrm{H}$ & $10.8(8.48,13.7)$ & $4.23(3.38,5.29)$ & $1.44(1.11,1.86)$ \\
& $\mathrm{N}$ & $0.14(0.02,1.02)$ & $1.65(1.07,2.55)$ & $1.89(1.26,2.83)$ \\
Shigella & $\mathrm{H}$ & $0.25(0.06,1.01)$ & $1.26(0.82,1.94)$ & $1.48(1.00,2.20)$ \\
& $\mathrm{N}$ & $1.74(1.14,2.65)$ & $4.57(3.59,5.81)$ & $2.52(1.96,3.24)$ \\
Yersinia & $\mathrm{H}$ & $2.24(0.92,5.44)$ & $6.02(3.51,10.3)$ & $3.98(2.30,6.88)$ \\
& $\mathrm{N}$ & $9.30(8.21,10.5)$ & $6.27(5.61,7.00)$ & $1.06(0.92,1.22)$ \\
\hline
\end{tabular}

missing ethnicity data subsequently decreased markedly to around 3.5\%. For all the diseases except Salmonella typhi and Shigella, notification rates in Mãori children were approximately 60 to $70 \%$ lower than in non-Māori children (Table 4). Ethnic differences in hospitalization rates were only evident for Campylobacter $(p<0.001)$ and nontyphoidal Salmonella $(p=0.003)$, and suggestive for Cryptosporidium $(p=0.066)$. Shigella was the only disease that suggested higher hospitalization rates in Māori $(p=0.092)$.

\section{Discussion}

This is the first study in NZ to analyze longitudinal data on childhood gastroenteritis caused by non-viral pathogens. The trend towards a decline in both notifications and hospitalizations for most non-viral pathogens included in this study is reassuring. Most of these pathogens are predominantly foodborne, and the observed decline may have been contributed to by changes in food safety, such as food industry standards relating to food handling and general hygiene, as well as increased consumer awareness of food safety [24]. The decline may also have been contributed to by changes in the food production sector, including farming, such as increased mechanization and more stringent monitoring of food safety indicators.

Consistent with several other international studies [25-27], Campylobacter was identified as the pathogen associated with the majority of notifications and hospitalizations. Hospitalization rates increased and decreased in parallel with notification rates, thus it is unlikely these results are artefactual. Our results are consistent with trends observed in the adult population in NZ, in

Table 4 Differences in notification and hospitalization rates by gender and ethnicity. Values represent incidence rate ratios (95\% confidence intervals) adjusted by year and age

\begin{tabular}{|c|c|c|c|c|}
\hline & Male vs. Female & & Māori vs. non-M & \\
\hline & Notifications & Hospitalizations & Notifications & Hospitalizations \\
\hline Campylobacter & $1.43(1.35,1.51)$ & $1.51(1.35,1.69)$ & $0.27(0.25,0.30)$ & $0.60(0.52,0.70)$ \\
\hline Cryptosporidium & $1.16(1.04,1.30)$ & $0.91(0.73,1.14)$ & $0.34(0.28,0.41)$ & $0.74(0.54,1.01)$ \\
\hline ETEC & $1.00(0.90,1.12)$ & $0.88(0.67,1.15)$ & $0.43(0.36,0.51)$ & $0.98(0.68,1.41)$ \\
\hline Giardia & $1.25(1.17,1.33)$ & $1.08(0.83,1.40)$ & $0.31(0.27,0.34)$ & $1.13(0.82,1.56)$ \\
\hline Nontyphoidal Salmonella & $1.11(1.02,1.20)$ & $1.03(0.88,1.20)$ & $0.37(0.32,0.42)$ & $0.72(0.59,0.89)$ \\
\hline Salmonella typhi & $1.01(0.74,1.39)$ & $1.03(0.77,1.37)$ & $0.72(0.27,1.94)$ & $1.24(0.20,7.55)$ \\
\hline Shigella & $1.04(0.82,1.31)$ & $0.80(0.61,1.05)$ & $0.80(0.56,1.12)$ & $1.41(0.95,2.09)$ \\
\hline Yersinia & $1.25(1.15,1.35)$ & $0.95(0.76,1.19)$ & $0.34(0.30,0.39)$ & $1.15(0.83,1.60)$ \\
\hline
\end{tabular}


which notification rates for Campylobacter peaked in 2006 (> 380 per 100,000) and were lowest in $2008(161.5$ per 100,000) [10].

Between 2004 and 2008, and most notably between 2006 and 2008, there was a reduction in Campylobacter notifications that was consistent across all age groups. This reduction coincided with the introduction of a range of voluntary and regulatory interventions to reduce Campylobacter contamination in poultry [28]. In late 2006, the NZ Food Safety Authority (formerly part of the Ministry of Agriculture and Fisheries - now the Ministry for Primary Industries) released guidance aimed at reducing the incidence of poultry-associated foodborne Campylobacter disease. This was in response to research that indicated poultry contributed disproportionately to the incidence of Campylobacter disease in NZ [28, 29]. Interventions included the development and implementation of microbiological surveillance activities and increased reporting. The observed reduction in Campylobacter incidence in children seen in this study provides evidence of the positive effects of a food safety measure on child health. Whilst these findings are encouraging, there is some suggestion from our analysis that Campylobacter notification rates may have plateaued since 2008. This may, in part, be attributable to recent outbreaks, which have been water, rather than food-borne, or other changes such as the increasing popularity of the consumption of raw milk. This observation warrants purposeful surveillance.

Nontyphoidal salmonellae are also common bacterial pathogens associated with acute gastroenteritis in children $[26,30]$ and the leading cause of childhood bacterial enterocolitis requiring hospitalisation [31]. Although the food safety interventions mentioned above were targeted predominantly at Campylobacter, they may also have served to reduce the incidence of disease due to nontyphoidal Salmonella, which is also commonly transmitted via poultry. The observed reduction in the incidence of nontyphoidal Salmonella between 1997 and 2016 (as for Campylobacter) supports this hypothesis.

Unlike for nontyphoidal Salmonella, the rates of notification and hospitalization for Salmonella typhi were very similar. This finding is not surprising given that infection with Salmonella typhi is more likely to present with severe disease requiring hospitalization.

The number of notifications of ETEC infection increased steadily after 1997, reaching a peak of 16 cases per 100,000 in the population across all age groups in 2016. This increase may, in part, be due to changes in laboratory testing practices over that period, with increasingly sensitive assays and algorithms used for the detection of Escherichia coli (E. coli) [32] It could also have been contributed to by improvements in surveillance due to increased public health concern [32]. However, the increased rates of notification and hospitalization in the under one and
1-4 year age groups compared to those $>5$ years are notable. Jaros et al. (2014) reported that the highest rate of $E$. coli infections in their national prospective case-control study of confirmed cases of Shiga toxin-producing E. coli in NZ occurred in the 1-4 year age group. The risk to children was increased further if there was a family member in contact with animals other than household pets. That study provides some support for the contention that the higher rates of disease in babies and children under 5 years of age found in our study is unlikely to be accounted for by changes in laboratory testing practices in those $\leq 4$ years of age.

Exposures to farming environments have been reported as risk factors of sporadic ETEC infections, particularly in young children [33, 34]. Sheep and, in particular, cattle, are considered an important reservoir for ETEC and are the primary source of foodborne and environmental outbreaks in humans [32]. Our study observed higher rates of ETEC infections in DHB regions with more intensive dairy farming compared to those DHB regions with less intensive dairy farming (Additional file 1: Figure S1).

Māori children had lower notification rates for disease when compared to non-Māori children. This is an unexpected finding. A previous study has reported that risk for morbidity due to infectious disease is higher in Māori compared to non-Māori, and also that infectious disease incidence in Māori has risen considerably over time, resulting in pronounced gradients of disease inequality [35]. However, a lower incidence of Campylobacter in Māori adults has been reported previously $[8,36]$. Despite Māori people being more likely to live in farming regions [37], their incidence of notified Campylobacter disease does not correspond with the higher rates seen overall in these areas. Disparities in Mãori access to health care are well documented and may be contributing to the lower rates of notification in this population [38]. In order for notification to occur, children must present to a health care provider and be tested. Hence, the results observed could be due to lower rates of both presentation and subsequent testing.

\section{Strengths and limitations}

NZ has a robust disease notification system regulated under the Health Act 1956. Notification can be initiated on the basis of 'clinical suspicion' by a medical practitioner, but is usually based on the isolation of a pathogen from a clinical sample. All admissions to public hospitals are recorded and data on hospital admissions collated and held nationally. This study has used data from the two most comprehensive national datasets in our analysis.

It is widely accepted that the incidence of gastroenteritis in NZ is underreported. Lake et al. (2010) reported that for every notified case of acute gastroenteritis in NZ, there were an estimated 222 cases in the community that were 
not reported [7]. It is estimated that $0.4 \%$ of community cases of acute gastroenteritis are notified to the national surveillance system [39]. Recent changes to reporting methods, alongside improvements to ETEC testing and detection, raise the possibility that there could have been more systematic underreporting and subsequent underestimation of disease earlier on in the study period.

Although considerable evidence has been published suggesting that interventions implemented by the food industry may have contributed to the decline in the incidence of Campylobacter gastroenteritis and disease due to nontyphoidal Salmonella in NZ, several alternative explanations should be considered. These include the possibility of surveillance artifact, a decline in the relative proportion of food versus waterborne disease, and changes in consumer behavior, such as increased awareness of food hygiene.

Our observations in Māori children regarding the low rates of notification are concerning and warrant further investigation. Of note, almost one fifth of cases were missing ethnicity data in ESR EpiSurv records prior to 2009, although the proportion of cases with missing ethnicity data decreased markedly after that. As such, differences in rates by ethnicity prior to 2009 should be interpreted with caution. Misclassification of ethnicity is also of concern and may have contributed to underestimation of disease incidence in Māori children.

\section{Conclusions}

The burden of disease due to non-viral gastroenteritis in NZ children is highest in the community setting. The overall incidence of these infections is reducing over time with only a small proportion of cases needing hospital admission. Disparities in access to healthcare may have led to Māori children having lower rates of notification for non-viral gastroenteritis, and this warrants further investigation. This study provides an important insight into the non-viral causes of gastroenteritis in NZ and how changes in food safety practices may have helped to reduce the burden of these diseases in children. It also highlights the potential importance of other environmental influences on the incidence of some of the most serious of these infections, disease due to ETEC.

\section{Additional file}

Additional file 1: Figure S1. Notification rates for ETEC by District Health Board. Points represent observed crude incidence. Lines and shading represent incidence with 95\% confidence intervals predicted by Poisson regression models assuming a constant annual percentage change (APC). The APC is displayed in text with 95\% confidence interval. Key: Areas with intensive dairy farming. Percentages represent the regional distribution of dairy cows (2016/17): North Island of NZ: Waikato (23.0\%), Taranaki (9.7\%), Northland (5.5\%). South Island of NZ: Canterbury (13.8\%), Southern (11.6\%), Otago (5.3\%), South Canterbury (5.0\%). * All others $<5 \%$. (EPS $61 \mathrm{~kb}$ )

\section{Abbreviations}

AAPC: Average annual percentage change; DHB: District Health Board; ESR: The Institute of Environmental Science and Research Ltd.; ETEC: Verotoxin-producing or shiga toxin-producing enterotoxigenic Escherichia coli; ICD-9-CM codes: International Classification of Diseases - Clinical Modification 9; MoH: Ministry of Health, New Zealand; NMDS: National Minimum Dataset; NZ: New Zealand; WHO: World Health Organization

\section{Acknowledgements}

The authors wish to thank CureKids New Zealand for funding this study.

\section{Funding}

This study was funded by CureKids New Zealand. Curekids had no role in the design of the study, collection, analysis and interpretation of the data, nor manuscript preparation.

\section{Availability of data and materials}

The data that support the findings of this study are available from The Institute of Environmental Science and Research Ltd. (ESR) and The Ministry of Health (NMDS) but restrictions apply to the availability of these data, which were used under license for the current study, and so are not publicly available. Data are however available from the authors upon reasonable request and with permission of The Institute of Environmental Science and Research Ltd. (ESR) and The Ministry of Health (NMDS).

\section{Authors' contributions}

All authors contributed to the conception of the paper. EJ completed this study as a student project during her fourth year of medical school. TW, JW, NM and CB were supervisors. JW conducted data analysis. EJ, TW and JW drafted the manuscript. All authors have made important intellectual contributions to manuscript draft revisions. All authors have read and approved the final manuscript.

\section{Authors information}

EJ (BSc, PG Dip Diet, NZRD, MHealSc) is a fifth-year Medical Student (MB ChB) at the University of Otago, Christchurch School of Medicine, New Zealand. She is a qualified Paediatric Dietitian and holds a Masters Degree in Health Sciences. Her research interests include the epidemiology of infectious diseases in children, and risk-attenuation strategies related to maternal obesity in pregnancy.

JW (BSc(Hons), MBiostat, PhD) is a Biostatistician for the Department of Population Health, University of Otago, Christchurch, New Zealand. JW completed a PhD in Immunology before pursuing a career in population-based health. JW has focused his research and professional career on developing population-based health innovations and reducing health inequalities. He has experience in conducting a diversity of research including laboratory studies, surveillance and epidemiological studies, and clinical trials.

NM (BHB MB ChB, Dip. Paeds, FRACP, DPhil) is a Consultant Paediatrician at the University of Otago, Christchurch, New Zealand. She worked as a clinical research fellow in the Department of Pediatrics, University of Oxford, United Kingdom from 2012 to 2015 and completed a DPhil in Pediatrics at Oxford University in 2018. She is extensively involved in a current UK multicentre cohort study of childhood central nervous system infection, in addition to epidemiological studies.

CB (MB ChB, DipComH, FAFPHM) is a Public Health Physician. CB spent a decade working in general practice and emergency medicine before retraining as a public health medicine specialist. Since then she has worked as a Senior Lecturer in Public Health at the University of Otago, Christchurch and as a public health specialist with the Canterbury District Health Board. She is also a Medical Officer of Health. Her research interests are in the epidemiology of viral hepatitis, influenza and other vaccine preventable disease, and water-borne disease. TW (MB ChB, FRACP, MD) is an Infectious Diseases Specialist, General Paediatrician and Associate Professor of Paediatrics, University of Otago, Christchurch, New Zealand. TW completed his clinical training in Pediatrics in New Zealand and specialist training at Great Ormond St Hospital for Children in London, United Kingdom. Following the completion of his specialist training, he worked for several years as an Infectious Diseases Specialist at Sydney Children's Hospital. He has a longstanding interest in viral infections in children and completed an M.D. through the University of London on adenovirus infections in children post-stem cell transplantation. His current research interests include vaccinations and their safety, as well as bone and joint infections in preschoolers. 


\section{Ethics approval and consent to participate}

This study was approved by the University of Otago Human Ethics Committee (Health), ethics reference number HD16/057. This approval was required by the Ministry of Health and ESR in advance of the study to get access to the NMDS and ESR databases. Consent by individuals was not required for this study as this was routinely collected and de-identified data.

\section{Consent for publication}

Not applicable.

\section{Competing interests}

The authors declare that they have no competing interests.

\section{Publisher's Note}

Springer Nature remains neutral with regard to jurisdictional claims in published maps and institutional affiliations.

\section{Author details}

'Department of Paediatrics, University of Otago, PO Box 4345, Christchurch Mail Centre, Christchurch 8140, New Zealand. ${ }^{2}$ Department of Population Health, University of Otago, PO Box 4345, Christchurch Mail Centre, Christchurch 8140, New Zealand.

\section{Received: 4 June 2018 Accepted: 19 November 2018}

\section{Published online: 05 January 2019}

\section{References}

1. Guarino A, Albano F, Ashkenazi S, Gendrel D, Hoekstra JH, Shamir R, Szajewska H. European Society for Paediatric Gastroenterology, hepatology, and nutrition/European Society for Paediatric Infectious Diseases evidence-based guidelines for the management of acute gastroenteritis in children in Europe: executive summary. J Pediatr Gastroenterol Nutr. 2008;46:619-21.

2. Kirk MD, Pires SM, Black RE, Caipo M, Crump JA, Devleesschauwer B, Dopfer D, Fazil A, Fischer-Walker CL, Hald T, et al. World Health Organization estimates of the global and regional disease burden of 22 foodborne bacterial, protozoal, and viral diseases, 2010: a data synthesis. PLoS Med. 2015;12:e1001921.

3. Fletcher SM, McLaws ML, Ellis JT. Prevalence of gastrointestinal pathogens in developed and developing countries: systematic review and meta-analysis. J Public Health Res, 2013:2:42-53.

4. World Health Organization. Rotavirus vaccines. WHO position paper - January 2013. Wkly Epidemiol Rec. 2013:88:49-64.

5. Kelly MJ, Foley D, Blackmore TK. Hospitalised rotavirus gastroenteritis in New Zealand: the laboratory database is a valuable tool for assessing the impact of rotavirus vaccination. Vaccine. 2017;35:4578-82.

6. Grimwood K, Huang QS, Cohet C, Gosling IA, Hook SM, Teele DW, Pinnock RE, Nicholson WR, Graham DA, Farrell AP, et al. Rotavirus hospitalisation in New Zealand children under 3 years of age. J Paediatr Child Health. 2006:42:196-203.

7. Lake RJ, Adlam SB, Perera S, Campbell DM, Baker MG. The disease pyramid for acute gastrointestinal illness in New Zealand. Epidemiol Infect. 2010;138: 1468-71.

8. Adlam SB, Perera S, Lake RJ, Campbell DM, Williman JA, Baker MG. Acute gastrointestinal illness in New Zealand: a community study. Epidemiol Infect. 2011;139:302-8

9. Ministry of Health. Guidance on infectious disease management under the health act 1956. Wellington: Ministry of Health; 2017.

10. The Institute of Environmental Science and Research Ltd. Notifiable diseases in New Zealand Annual Report 2016. Porirua: The Institute of Environmental Science and Research Ltd; 2017.

11. Lopez L, Roos R, Cressey P, Hom B, Lee J. Foodborne disease in New Zealand 2015. MPI technical paper no: 2016/54. industries MfP ed. Ministry for Primary Industries: Wellington; 2016.

12. The Department of Internal Affairs. Government Inquiry into Havelock North Drinking Water. Report of the Havelock North Drinking Water Inquiry: Stage 2. Affairs TDol ed. Auckland: The Department of Internal Affairs; 2017

13. Ministry of Health. Annual update of key results 2015/16: New Zealand health survey. Wellington: Ministry of Health; 2016.

14. Investigating the causes of diarrhoeal illness [https:/www.esr.crinz/home/ about-esr/our-science-in-action/investigating-the-causes-of-diarrhoeal-illness/_
15. National Minimum Dataset (hospital events) [http://www.health.govt.nz/nzhealth-statistics/national-collections-and-surveys/collections/nationalminimum-dataset-hospital-events].

16. Voss L, Lennon D, Okesene-Gafa K, Ameratunga S, Martin D. Invasive pneumococcal disease in a pediatric population, Auckland, New Zealand. Pediatr Infect Dis J. 1994;13:873-8.

17. Schlapbach LJ, Straney L, Alexander J, MacLaren G, Festa M, Schibler A, Slater A. Mortality related to invasive infections, sepsis, and septic shock in critically ill children in Australia and New Zealand, 2002-13: a multicentre retrospective cohort study. Lancet Infect Dis. 2015;15:46-54.

18. Milne RJ, Lennon DR, Stewart JM, Vander Hoorn S, Scuffham PA. Incidence of acute rheumatic fever in New Zealand children and youth. J Paediatr Child Health. 2012:48:685-91.

19. O'Sullivan CE, Baker MG, Zhang J. Increasing hospitalizations for serious skin infections in New Zealand children, 1990-2007. Epidemiol Infect. 2011:139: 1794-804

20. Rothman KJ, Greenland S, Lash TL. Modern epidemiology. 3rd ed. Philadelphia: Lippincott Williams \& Wilkins; 2008.

21. Kim HJ, Fay MP, Feuer EJ, Midthune DN. Permutation tests for joinpoint regression with applications to cancer rates. Stat Med. 2000;19:335-51.

22. Statistical Methodology and Applications Branch SRP, National Cancer Institute. Joinpoint Regression Program, Version 4.5.0.1 Statistical Methodology and Applications Branch, Surveillance Research Program, National Cancer Institute; 2017

23. Wood SN. Generalized additive models: an introduction with R (2nd edition): Chapman and Hall/CRC; Florida. 2017.

24. Redmond EC, Griffith CJ. Consumer food handling in the home: a review of food safety studies. J Food Prot. 2003;66:130-61.

25. Kuhn KG, Nielsen EM, Molbak K, Ethelberg S. Epidemiology of campylobacteriosis in Denmark 2000-2015. Zoonoses Public Health. 2018;65:59-66.

26. Stutman HR. Salmonella, Shigella, and campylobacter: common bacterial causes of infectious diarrhea. Pediatr Ann. 1994;23:538-43.

27. OzFoodNet Working Group. Monitoring the incidence and causes of diseases potentially transmitted by food in Australia: annual report of the OzFoodNet network, 2011. Commun Dis Intell Q Rep. 2015;39:E236-64.

28. Sears A, Baker MG, Wilson N, Marshall J, Muellner P, Campbell DM, Lake RJ, French NP. Marked campylobacteriosis decline after interventions aimed at poultry, New Zealand. Emerg Infect Dis. 2011;17:1007-15.

29. Eberhart-Phillips J, Walker N, Garrett N, Bell D, Sinclair D, Rainger W, Bates M. Campylobacteriosis in New Zealand: results of a case-control study. J Epidemiol Community Health. 1997;51:686-91.

30. Chen SM, Ni YH, Chen HL, Chang MH. Microbial etiology of acute gastroenteritis in hospitalized children in Taiwan. J Formos Med Assoc. 2006;105:964-70.

31. Su LH, Chiu CH. Salmonella: clinical importance and evolution of nomenclature. Chang Gung Med J. 2007;30:210-9.

32. Jaros P, Cookson AL, Campbell DM, Besser TE, Shringi S, Mackereth GF, Lim E, Lopez L, Dufour M, Marshall JC, et al. A prospective case-control and molecular epidemiological study of human cases of Shiga toxin-producing Escherichia coli in New Zealand. BMC Infect Dis. 2013;13:450.

33. Werber D, Behnke SC, Fruth A, Merle R, Menzler S, Glaser S, Kreienbrock L, Prager R, Tschape H, Roggentin P, et al. Shiga toxin-producing Escherichia coli infection in Germany: different risk factors for different age groups. Am J Epidemiol. 2007;165:425-34

34. Rivas M, Sosa-Estani S, Rangel J, Caletti MG, Valles P, Roldan CD, Balbi L, Marsano de Mollar MC, Amoedo D, Miliwebsky E, et al. Risk factors for sporadic Shiga toxin-producing Escherichia coli infections in children, Argentina. Emerg Infect Dis. 2008;14:763-71.

35. Baker MG, Barnard LT, Kvalsvig A, Verrall A, Zhang J, Keall M, Wilson N, Wall T. Howden-Chapman P. Increasing incidence of serious infectious diseases and inequalities in New Zealand: a national epidemiological study. Lancet. 2012:379:1112-9.

36. Dong H, Mitchell P. Community and Public Health, Canterbury District Health Board: South Island Campylobacteriosis. A review of notifications 2010-2012 by district health board. Christchurch: Canterbury District Health Board; 2013.

37. 2013 Census QuickStats about Măori. [http://wwww.stats.govt.nz/Census/2013census/profile-and-summary-reports/quickstats-about-maori-english.aspx].

38. Minister of Health and Associate Minister of Health. Whakatātaka Tuarua: Mãori Health Action Plan 2006-2011. Wellington: Ministry of Health; 2006.

39. Lake R, Adlam B, Perera S. Acute Gastrointestinal Illness (AGI) Study: Final Study Report. (ESR) loESaRL ed. Christchurch: Institute of Environmental Science and Research Ltd (ESR); 2009. 